\title{
Article \\ Development of an Analytical Model for the FRP Retrofitted Deficient Interior Reinforced Concrete Beam-Column Joints
}

\author{
Asad Zia ${ }^{1,2}$, Zhang Pu ${ }^{1, *}$, Ivan Holly ${ }^{2}$, Tariq Umar ${ }^{3}\left(\mathbb{D}\right.$ and Muhammad Atiq Ur Rehman Tariq ${ }^{4,5}$ \\ 1 School of Civil Engineering, Zhengzhou University, Zhengzhou 450001, China; asadzia005@gs.zzu.edu.cn \\ 2 Department of Concrete Structures and Bridges, Slovak University of Technology, 81243 Bratislava, Slovakia; \\ ivan.holly@stuba.sk \\ 3 Department of Architecture and the Built Environment, Faculty of Environment and Technology, \\ University of the West of England, Bristol BS161QY, UK; tariq.umar@uwe.ac.uk \\ 4 Institute for Sustainable Industries \& Liveable Cities, Victoria University, P.O. Box 14428, \\ Melbourne 8001, Australia; atiq.tariq@yahoo.com \\ 5 College of Engineering and Science, Victoria University, Melbourne 8001, Australia \\ * Correspondence: zhpu@zzu.edu.cn; Tel.: +86-135-2300-9543
}

Citation: Zia, A.; Pu, Z.; Holly, I.; Umar, T.; Tariq, M.A.U.R.

Development of an Analytical Model for the FRP Retrofitted Deficient

Interior Reinforced Concrete

Beam-Column Joints. Appl. Sci. 2022, 12, 2339. https://doi.org/10.3390/ app12052339

Academic Editor: Kang Su Kim

Received: 12 January 2022

Accepted: 22 February 2022

Published: 23 February 2022

Publisher's Note: MDPI stays neutral with regard to jurisdictional claims in published maps and institutional affiliations.

Copyright: (C) 2022 by the authors. Licensee MDPI, Basel, Switzerland. This article is an open access article distributed under the terms and conditions of the Creative Commons Attribution (CC BY) license (https:// creativecommons.org/licenses/by/ $4.0 /)$.

\begin{abstract}
Beam-column joints (BCJs) constructed until the 1970s carry a low shear capability due to the absence of shear reinforcement. Fiber-reinforced polymers (FRP) are more reliable than other materials to strengthen a weak BCJ. To date, plenty of analytical models have been developed to analyze the actual contribution of the FRP to the shear strength of RC BCJs. However, the models developed are either too complex in computational efforts or based on empirical coefficients that result in compromised results. The models that formulate the contribution of FRP to the shear strength of the FRP-strengthened deficient interior BCJ are very limited, and such models are too complex. An adequate BCJs' FRP strain equation must still be developed to address these issues. Therefore, the FRP effective strain equation and contribution of FRP to RC BCJs are derived in this research work using an updated database of the appropriate BCJs. The initial analytical model of Bousselham, which Del Vecchio later improved, is further extended to FRP-strengthened deficient interior BCJs. For this purpose, an updated database of the 32 tests around the world of FRP-strengthened interior BCJs deficient in seismic reinforcement is prepared. Firstly, the experimental effective FRP strain is derived using the experimental database. Then, a power-type equation is derived for the effective FRP strain by considering the crucial parameters of the FRP-strengthened interior BCJs. Finally, the experimental shear strengths and those determined with the proposed equation of the FRP-strengthened joints are compared. The average ratio between the experimental and analytical (proposed model) joint shear strengths of the considered specimens ensured the accuracy of the suggested model. The suggested approach makes computing the FRP enhancements required to avoid shear failure in interior joints easy and reliable for researchers and field engineers interested in seismically reinforcing existing structures.
\end{abstract}

Keywords: FRP strengthening; analytical model; under-designed RC joints; effective FRP strain; interior beam-column joints

\section{Introduction}

During earthquakes, the RC beam-column joints are the most susceptible element of the RC structure [1]. Consequently, numerous strengthening strategies were reported to enhance the capability of contemporary beam-column joints (BCJs) during seismic events [2]. Among the materials utilized by the researchers for this purpose, there are steel fibers [3], RC jackets [4], RC chamfers [5], fiber-reinforced composites ([6], hybrid fiber reinforced concrete with ultra-high performance [7], FRP laminates [8], CFRP ropes [9], geosynthetic materials [10], and sheets and strips of fiber-reinforced polymers (FRP) [11-13]. Compared to other techniques, FRP systems are more popular as a strengthening solution 
because of their light weight [14], durability, ductility, significant resistance to corrosion, and easy handling [15-18]. Therefore, the focus of the research will be FRP systems.

Most of the recommended approaches for strengthening or retrofitting beam-column junctions were determined to be appropriate, as evidenced by the testing findings. However, developing a standard and universal analytical model or technique for analyzing the behavior of beam-column joints reinforced with various types of retrofitting schemes remains a challenge. The analytical models of beam-column joints differ in strengthening procedures and materials. The objective of all analytical models was to determine how much the shear strength of the beam-column junction increased because of joint confinement by the strengthening approach. The shear strength of the joint is utilized to specify the contribution of the applied strengthening procedure in the majority of the analytical models $[19,20]$. In the procedures provided by codes and standards for the design of structures strengthened with externally bonded FRP (American Concrete Institute ([21]; Canadian Standards Association [22]; Fédération Internationale du Béton [23]; National Research Council (CNR) [24], there are no expressions for determining the increased strength of beam-column joints strengthened with FRP or other materials. There are several analytical models for various strengthening procedures in the literature review. However, each analytical model has flaws that make it impossible to apply in certain circumstances or is dependent on assumptions. As a result, the findings were different from the actual model.

Pantazopoulou and Bonacci's model [25] is the first analytical model of the FRP reinforced beam-column connection. Many assumptions were made, such as the beam-column reinforcements not degrading in bond and the joint being properly detailed, preventing it from being utilized for pre-seismic joints. Later, Antonopoulos and Triantafillou [26] proposed an expanded version of Pantazopoulou and Bonacci's hypothesis [25]. Stress equilibrium and strain compatibility in the joint core were used to create formulas to characterize various damage-limit states associated with the crushing of concrete or the debonding or failure of the FRP. However, the suggested model attracted little attention due to the intricacy of the resultant equations and the substantial computational effort necessary in its practical implementation. Antonopoulos and Triantafillou's work was expanded by [27]. The approach is then extended to calculate the diagonal tensile stresses of the joint. Due to the intricacy of the resulting equations and the requirement for significant computing effort for implementation, this model, similar to Antonopoulos and Triantafillou's [26], received little attention.

Tsonos [28] demonstrated a design technique to estimate joint shear (JS) stress. There were two major flaws in the suggested model. The first problem is that it is difficult to justify the usage of FRP jackets to enclose the joint core completely because a substantial portion of a square or rectangular portion, such as the cross-section of joints, remains unwrapped even when entirely wrapped. Second, test findings on FRP-reinforced columns appear to have been used to construct an equation for predicting the enhanced joint concrete compressive strength owing to confinement, because the column analogy is not relevant for estimating joint shear stress [29]. Bousselham [20] also developed a method for measuring the shear strength of FRP-strengthened external RC beam-column junctions. Unfortunately, the FRP's effective strain was restricted to 0.4 percent in most situations, which severely understated the FRP's performance.

Del Vecchio [19] provided an analytical model based on the same technique as Bousselham [20]. Bousselham's methodology for calculating the effective FRP strain is that at the joint panel's peak strength, the FRP comes in effect. According to experimental data on the FRP strengthening of the joint, the usefulness of FRP fibers begins at the junction panel breaking [30]. The Bousselham [20] model's two flaws were overcome by evaluating FRP effective at the joint panel's first fracture rather than peak strength and not restricting FRP effective strain to 0.4 percent. Both models came up with a formula for the FRP effective strain. Both models' equations were calibrated using test data from RC beam-column sub-assemblages with fiber failure in the literature, i.e., 
fiber rupture or fiber debonding only. Bousselham [20] derived an equation of FRP effective strain for exterior beam-column joints only. An equation for FRP effective strain of internal beam-column joints was not derived because there is a scarcity of test data on interior beam-column sub-assemblages in the literature. Therefore, the expression derived by [19] for the FRP effective strain of the beam-column joints is also limited to the corner beam-column joints. Besides, due to the unavailability of enough experimental test results at that time (i.e., 2010 for Bousselham [20] and 2015 for Del Vecchio [19]), re-calibration and modification of the expression of the FRP effective strain were impossible according to the outlined method.

Okahashi and Pantelides [31] compared a detailed interior beam-column joint reinforced with FRP sheets or strips to an expanded strut-and-tie model of the exterior and interior RC beam-column connections. However, the technique for adding the tensile strength of FRP and its contribution to the joint's shear strength and diagonal compression strength is not well defined. Akguzel and Pampanin [32] developed a technique for estimating the increase in the shear strength of the FRP-strengthened exterior beam-column joints due to FRP composites. A semi-empirical analytical approach was used to assess the shear strength of FRP retrofitted joints. Nevertheless, the model was semi-empirical, and unique empirical factors based on experience were utilized to estimate the shear strength of FRP reinforced beam-column joints. In addition, Tasligedik [33] also used the hierarchy of strength assessment for estimating the capacity of the FRP-strengthened interior and exterior beam-column joints. Nevertheless, the method included empirical coefficients (c1 is empirically reported as $\mathrm{c} 1=0.64$ by [34] and $\mathrm{c} 2=2.0$ reported by FIB) [35]. Moreover, the model presented was verified with a limited number of specimens.

Given the preceding discussion of current analytical models, it was necessary to develop an analytical model for FRP-strengthened, under-designed interior BCJs that could address the shortcomings of the prior models. The complexity of the procedures, the lack of updated data of experimental results of under-designed RC BCJs, the lack of general equations for interior FRC-strengthened under-designed RC BCJS, the use of empirical equations based on assumptions, and the use of techniques that require high computational efforts to determine the contribution of FRP are all issues that have been identified thus far.

As a result, the current study presents an analytical model free of the problems and flaws stated above. The current study suggests a novel and different analytical model free of the issues and flaws stated above. The relevant analogy is used to calculate the joint shear stress, and the column analogy is avoided. The model's implementation or use is straightforward without involving complex equations and high computational efforts. The effective FRP strain is fine-tuned based on updated experimental results (2021). The effective (maximum) FRP strain is not restricted to $0.4 \%$. The mechanical properties of joints, methods of FRP strengthening, and causes of failure are taken into account in calculating the effective FRP strain. The use of empirical equations and assumptions is avoided for reliable results.

To calculate the increase in the shear capacity of non-seismic internal beam-column joints due to FRP strengthening, the effective FRP strain is recommended to be fine-tuned. Based on updated experimental results (2021), the paper proposes a comprehensive analytical model that considers mechanical properties of joints, methods of FRP strengthening, and causes of failure. Bousselham's [20] approach (later utilized by Del Vecchio [19] for corner non-seismic RC BCJs) is expanded to obtain an equation for the effective FRP strain for substandard interior joints. The current updated and extensive database of experimental testing of FRP reinforced inadequate RC BCJs will be used to determine the effective FRP strain equation. 


\section{Experimental Database of Internal Beam-Column Joints}

A database of all accessible investigations related to interior beam-column joints was studied. The research studies related to FRP-strengthened interior deficient RC beamcolumn joints (BCJs) were studied, containing more than 32 tests worldwide. Some of these tests were unsuitable to be utilized in the current study due to various shortcomings such as concrete replacement with high strength concrete and use of CFRP plate by replacing concrete within the joint section [36], joints were not strengthened with FRP (JI1 by [37,38] and NA2, NA3, NB4, and NB5 by [12]), injecting an epoxy glue into the minor fissures, and repairing cracks before applying FRP (for NCIR, NC2R by [12]). Hence, only 17 tests were provided with details required for deriving an equation, excluding those inappropriate tests for our research, deemed inadequate or questionable. A brief view of this built database is given in Table 1. All test specimens are one-third or larger size subassemblies of RC frames. All specimens possessed statical determinacy and were cyclically loaded. In most of the investigations, the cyclic load was applied at the ends of the beams, whereas the translation of the column ends was restricted. However, for limited studies, the load was applied at the column ends, and the beam ends were restrained from translation.

The database includes all applicable information, such as the mechanical properties of the materials used, subassembly characteristics, the average of the maximal tip load in the push and pull directions that is used, member dimensions, FRP retrofitting properties, and experimentally determined parameters. Concrete with cylinder compressive strength $\left(f_{c}\right)$ varying from $25 \mathrm{MPa}$ to $43 \mathrm{MPa}$ was utilized. All reported specimens failed by joint strength crossed over by or combined with FRP debonding FD or FRP rupture FR. Other failure mechanisms that were reported include beam failure $\mathrm{BH}$, column failure or hinge $\mathrm{CF} / \mathrm{H}$, and bond-slip BS. For the entire 17 samples, fiber rupture or fracture is noticed except for three samples. 
Table 1. Experimental database on non-seismic interior joints strengthened with FRP.

\begin{tabular}{|c|c|c|c|c|c|c|c|c|c|c|c|c|c|c|c|c|c|c|c|}
\hline \multicolumn{4}{|c|}{ Subassembly Characteristics } & \multicolumn{3}{|c|}{$\begin{array}{c}\text { Member } \\
\text { Dimensions }\end{array}$} & \multicolumn{9}{|c|}{ FRP Strengthening Properties } & \multicolumn{4}{|c|}{$\begin{array}{c}\text { Parameters Determined } \\
\text { Experimentally }\end{array}$} \\
\hline Test Code $^{a}$ & $\begin{array}{l}\text { Mode of } \\
\text { Failure }\end{array}$ & $\begin{array}{c}f_{c} \\
(\mathrm{MPa})\end{array}$ & $N(\mathbf{k N})$ & $\begin{array}{c}b_{c} \\
(\mathrm{~mm})\end{array}$ & $\begin{array}{c}h_{c} \\
(\mathrm{~mm})\end{array}$ & $\left.\begin{array}{c}h_{b} \\
(\mathrm{~mm})\end{array}\right)$ & $\begin{array}{c}\text { Fiber } \\
(-)\end{array}$ & $\begin{array}{c}E_{f} \\
(\mathrm{GPa})\end{array}$ & $\begin{array}{l}b \\
\left({ }^{\circ}\right)\end{array}$ & $\begin{array}{c}t_{f} \\
(\mathrm{~mm})\end{array}$ & $\begin{array}{l}n_{l} \\
(-)\end{array}$ & $\begin{array}{l}n_{s} \\
(-)\end{array}$ & $\underset{(-)}{N s t r}$ & $\begin{array}{c}W_{f} \\
(\mathrm{~mm})\end{array}$ & $\begin{array}{c}\text { FRPP } \\
\text { Roperties }\end{array}$ & $\begin{array}{l}v_{j h}{ }^{\exp } \\
\text { (MPa) }\end{array}$ & $\begin{array}{c}\theta^{\exp } \\
\left({ }^{\circ}\right)\end{array}$ & $\begin{array}{c}A_{f, e q} \\
\left(\mathrm{~mm}^{2}\right)\end{array}$ & $e f_{e f f}{ }^{e x p}$ \\
\hline PRO(L4) & $\mathrm{CH}$ & 36.5 & 124.5 & 200 & 200 & 200 & CFRP & 264 & 90 & 0.165 & 1 & 2 & - & - & $\mathrm{C}$ & 11.68 & 48.81 & 44 & - \\
\hline $\mathrm{PRO}(\mathrm{H} 4)$ & $\mathrm{CH}$ & 39.8 & 249 & 200 & 200 & 200 & CFRP & 264 & 90 & 0.165 & 1 & 2 & - & - & $\mathrm{C}$ & 14.55 & 51.05 & 42 & - \\
\hline AL-SA(IR1) & FD, JS & 30 & 288 & 160 & 160 & 300 & CFRP & 61.5 & 0 & 1 & 1 & 2 & - & - & C-I & 6.46 & 57.47 & 588 & 0.0087 \\
\hline AL-SA(IS1) & FD, BH & 30 & 288 & 160 & 160 & 300 & CFRP & 61.5 & 0 & 1 & 1 & 2 & - & - & $\mathrm{C}$ & 8.56 & 54.67 & 567 & 0.0167 \\
\hline AL-SA(IR2) & FD, JS & 25 & 150 & 160 & 160 & 300 & CFRP & 61.5 & 0 & 1 & 1 & 2 & - & - & M-I & 6.73 & 51.55 & 546 & 0.0155 \\
\hline PAN(R24-3) & FD, JS & 43 & 709 & 406 & 406 & 406 & CFRP & 43 & 60 & 1.35 & 2 & 2 & - & - & U wraps & 7.10 & 53.44 & 2532 & 0.0095 \\
\hline PAN(R24-4) & FD, JS & 43 & 709 & 406 & 406 & 406 & CFRP & 106 & 60 & 1.02 & 2 & 2 & - & - & U wraps & 6.58 & 54.06 & 1913 & 0.0043 \\
\hline PAN(R16-2) & FD, JS & 43 & 709 & 406 & 406 & 406 & CFRP & 80 & 60 & 0.76 & 2 & 2 & - & - & U wraps & 5.32 & 56.01 & 1425 & 0.0029 \\
\hline PAN(R16-3) & FD, JS & 43 & 709 & 406 & 406 & 406 & CFRP & 43 & 60 & 1.35 & 2 & 2 & - & - & U wraps & 5.77 & 55.23 & 2532 & 0.0038 \\
\hline PAN(R16-4) & FD, JS & 43 & 709 & 406 & 406 & 406 & CFRP & 106 & 60 & 1.02 & 2 & 2 & - & - & U wraps & 6.01 & 54.85 & 1913 & 0.0023 \\
\hline Lee (JI2) & $\mathrm{FF}$, JS & 27 & 432 & 400 & 300 & 400 & CFRP & 258 & 90 & 0.11 & 4 & 2 & - & - & $\mathrm{M}-\mathrm{C}$ & 8.01 & 49.80 & 630 & 0.0101 \\
\hline Allam (AR-2) & JS & 34.5 & 356 & 254 & 254 & 406 & CFRP & 140.7 & \pm 45 & 0.56 & 2 & 2 & - & - & C-I & 4.32 & 55.90 & 1627 & 0.0011 \\
\hline Allam (RS-G) & $\mathrm{CT}$ & 34.5 & 356 & 254 & 254 & 406 & GFRP & 26.2 & $0 / 90 / \pm 45$ & 0.10 & 10 & 2 & - & - & $\mathrm{C}$ & 8.99 & 50.44 & 2004 & - \\
\hline Allam (RS-MC) & FR, JS. & 34.5 & 356 & 254 & 254 & 406 & CFRP & 200 & $0 / 90 / \pm 45$ & 0.80 & 6 & 2 & - & - & C & 7.87 & 51.19 & 9300 & 0.0005 \\
\hline Attari (NR2) & FD & 39 & 100 & 100 & 100 & 150 & GFRP & 19.2 & 0 & 2 & 2 & 2 & - & - & C & 14.33 & 51.56 & 936 & 0.0154 \\
\hline
\end{tabular}

Note: the number in brackets denotes layouts of FRP inclined at numerous angles and associated characteristics. ${ }^{\text {a }} \mathrm{PRO}=\mathrm{Prota}$ [39], AL-SA $=\mathrm{Almusallam}$ and Al-Salloum [27], PAN $=$ Pantelides [40], Lee $=$ Lee [37], Allam $=$ Allam [41], Attari $=$ Attari [12]. ${ }^{\mathrm{b}} \mathrm{FD}=$ debonding of FRP, FF $=$ tensile failure of FRP, $\mathrm{BH}=$ beam's failure due to plastic hinge, $\mathrm{CH}=$ column's failure due to plastic hinge, $\mathrm{JS}=$ joint shear failure, $\mathrm{CT}=$ column toe failure. ${ }^{\mathrm{c}}$ FRP Strengthening System Characteristics: $\mathrm{ns}=$ strips number, $\mathrm{C}=$ continuous fabric, $\mathrm{M}=$ mechanically anchored, $\mathrm{I}=$ initially damaged, $\mathrm{S}=$ strips, $\mathrm{C}=$ continuous fabric. $\theta^{\exp }=$ Experimentally determined principal compressive stress inclination. 


\section{Expression for Effective FRP Strain of Interior Joints Derivation}

The procedure outlined by [19] for exterior deficient RC beam-column joints is extended to derive the expression for non-seismic interior RC beam-column joints (BCJs). First, the experimental effective FRP strain is initially derived using the available experimental database. Then, a power-type equation is derived in terms of modulus of elasticity and area of FRP fibers and concrete strength. Then, by using the same equation, the shear strength of the FRP-strengthened joints are determined and compared with that of the experimentally determined shear strength of the joints.

The following steps are followed for deriving the expression of effective FRP strain:

\subsection{Experimental Joint Shear Strength}

The experimental shear strength of the beam-column joints is calculated by using the following procedure instead [42].

\subsubsection{Horizontal Shear $\left(V_{j h}\right)$ over the Joint Core's Mid-Depth}

Equilibrium considerations are used to determine the horizontal shear acting at the joint's center, $V_{j h}$. The free-body of an inner beam-column sub-assembly between its points of contra flexure is shown in Figure 1a, which is typical of test specimens often used in laboratory studies for idealizing RC frame joints. At the beam tip, the beam is subjected to a reversed cyclic load $\left(P_{b 1}\right)$. The internal forces acting on the face of the joint core because of the applied seismic forces can be demonstrated, as given in Figure 1b. In Figure 1b, the " $T_{S 2}$ " is the compression force $\left(C^{\prime}\right)$ in the beam section on the opposite side of the joint, but using the horizontal equilibrium equation to the beam cross-section gives $C^{\prime}=T_{s 2}$ [43]. Therefore, $T_{s 2}$ is directly put in the equation by replacing $C^{\prime}$ with $T_{s 2}$.

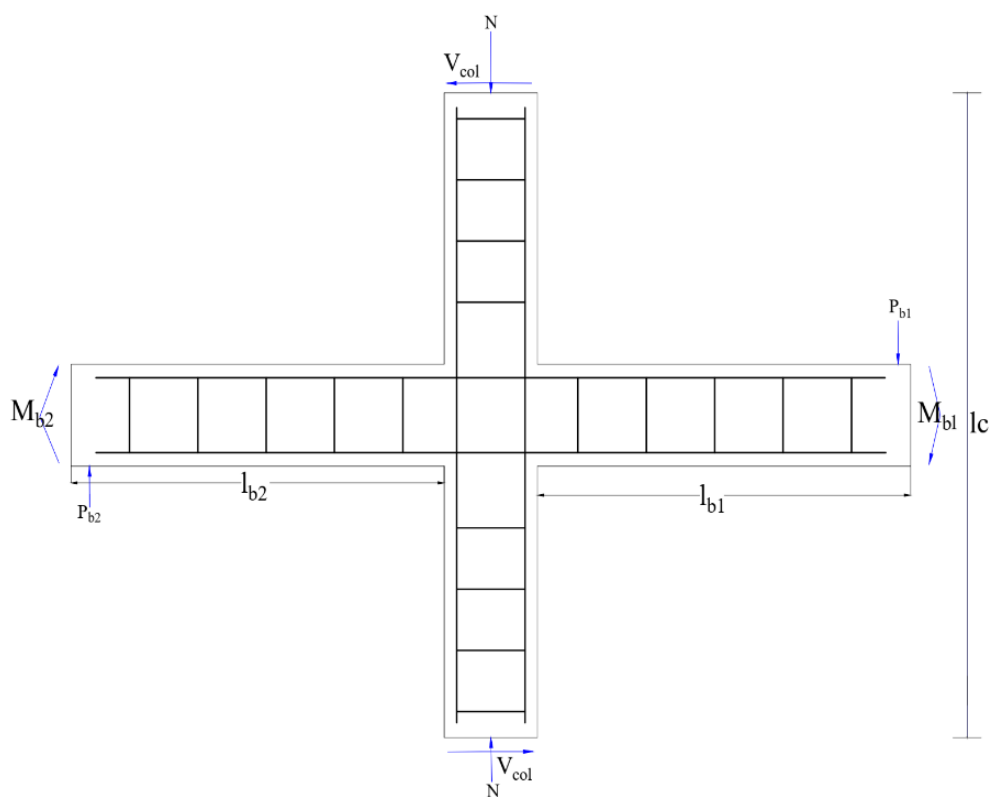

(a)

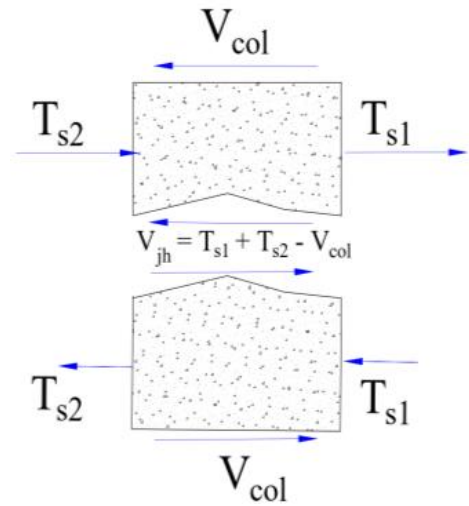

(b)

Figure 1. Joint shear of interior joint: (a) loading condition; (b) free body diagram at the mid-height of joint core.

The tension force in the beam bars framing into the joint (one or two forces depending on the exterior or interior joints) and the shear force from the column, $V_{c o l}$, acting in the opposite direction, creates the shear. This is in line with EC8 [44] and ACI 352R-02 [45] for joint shear demand evaluation:

$$
V_{j h}=T_{s 1}\left(+T_{s 2}\right)-V_{c o l}
$$


Forces in the Steel of the Beam $\left(T_{s 1}, T_{s 2}\right)$

The tension in the bars, $T_{s 1}$ and $T_{s 2}$, at the ultimate load $\left(P_{i}\right)$ at the tip of the beam or column, may be calculated by dividing the moment in the beam at the beam-joint interface, $M_{b i}$, by the lever $\left(j_{d}\right)$ between the centroid of compression forces and the tension forces operating in the joint. Where $j_{d}=d_{b}$ is the distance between the tension and compression resultants in the beam at the beam joint interface, estimated to be $0.75 h_{b}\left(h_{b}=\right.$ beam height $)$ in the lack of a more in-depth examination of all the possible joint set-ups in the literature. $J_{d}=0.75 h_{b}$ is also used by $[19,20]$.

$$
\begin{gathered}
T_{s 1}=\frac{M_{b 1}}{j_{d 1}} \\
T_{s 2}=\frac{M_{b 2}}{j_{d 2}} \\
\Rightarrow V_{j h}=\frac{M_{b 1}}{j_{d 1}}\left(+\frac{M_{b 2}}{j_{d 2}}\right)-V_{c o l}
\end{gathered}
$$

For symmetrical interior joints, $M_{b 1}$ and $M_{b 2}$ are considered to be equal, and $M_{b 1}$ may be determined from:

$$
M_{b 1}=P_{b 1} \cdot l_{b 1}
$$

The peak force applied at the beam tip is $P_{b 1}$, and the distance from the point on which the force acts and the joint interface is $l_{b 1}$. Thus, if a load is exerted at the column, for example, $P_{b 1}$ may be calculated from $P_{c}$, the ultimate force at the column tip, as follows:

$$
P_{b 1}=P_{c} \cdot l_{c} / W_{b}
$$

where $l_{c}$ refers to the entire test set-up's height (i.e., from the bottom column pin to the top column pin), and $W_{b}$ denotes the whole set-up's width (i.e., one beam length and column's half-width for exterior joints or both beams length and column width for interior joints).

Shear Force in Column $\left(V_{c o l}\right)$

If the force is acting at the column tip, the horizontal shear force $V_{c o l}$ is taken as $P_{c}$; if the force is exerted at the beam tip, equilibrium conditions may be used to calculate the force:

$$
V_{c o l}=P_{b 1} \cdot W_{b} / l_{c}
$$

Horizontal Shear Stress $\left(v_{j h}^{e x p}\right)$ over the Joint Core's Mid-Depth

The following equation is used for calculating the horizontal shear stress of the joint core.

$$
v_{j h}^{e x p}=\frac{V_{j h}}{A_{c o l}}=\frac{V_{j h}}{b_{c} \cdot h_{c}}=\frac{\frac{V_{b 1}}{j_{d 1}}\left(+\frac{V_{b 2}}{j_{d 2}}\right)-V_{c o l}}{b_{c} \cdot h_{c}}
$$

$j_{d}=d_{b}$ is the distance from the tension and compression resultants in the beam at the beam joint interface, which is considered $0.75 h_{b}$ ( $h_{b}=$ beam height). $j_{d}=0.75 h_{b}$ is also used by $[19,20] . P_{b 1}$ is the maximum tip load at the end of the beam taken from experimental test results of the FRP-strengthened beam-column joint. $l_{b 1}$ is the length of the beam measured between the column face and the actuator (point of load); $h_{c}=$ column's depth; $l_{c}=$ the height of the entire column; $b_{c}=$ width of the column; $P_{c}=$ maximum tip load at the end of the column taken from experimental test results.

\subsection{Developing an Equation for FRP Effective Strain}

Initially, the experimental effective FRP strain is derived using the available experimental database. Then, the power-type equation is derived in terms of elastic modulus and area of FRP fibers and concrete strength. Then, by using a similar equation, the shear strength of the FRP-strengthened joints are determined and compared with that of the 
experimentally determined shear strength of the joints. The procedure is briefly explained below.

i Equation of Effective FRP strain from experimental data:

$$
\varepsilon_{f, e}^{\exp }=\frac{\mathrm{p}_{t, f}^{\exp } \cdot b_{c} \cdot \mathrm{h}_{c}}{A_{f, e q} \cdot E_{f} \cdot \sin \theta}
$$

ii Calculation of parameters of Equation (9):

(a) The input of FRP to principal tensile stress as measured experimentally $\left(p_{t, f}^{\exp }\right)$ :

$$
p_{t, f}^{\exp }=\left(p_{t, t o t}^{\exp }\right)-\left(p_{c, t}\right)
$$

where $p_{t, f}^{e x p}$ is the total principal tensile stress of the interior beam-column joints strengthened with FRP, and $p_{c, t}$ refers to an increase in the principal tensile stress of the joint panel due to concrete.

Total principal tensile stress $\left(p_{t}=p_{t, t o t}^{\exp }\right)$ is determined by using Mohr's circle approach with the following equation:

$$
p_{t, t o t}^{\exp }=\frac{-\sigma_{c}}{2} \cdot \sqrt{\left(\frac{\sigma_{c}}{2}\right)^{2}+v_{j h}^{2}}
$$

Contribution of concrete in principle tensile stress for the deformed bar, interior $\mathrm{BCJ}$ is determined by using:

$$
p_{t, c}=\mathrm{k} \cdot \sqrt{f_{c}}
$$

When deformed bars are utilized (during the joint's initial breaking), the numerical coefficient $k$ is taken as 0.29 and when 0.42 is used (at the peak strength). At $k=0.20$, maximum peak strength and joint breaking are achieved for smooth internal reinforcement (Priestley 1997; Eurocode, C. E. N. 2004; Del Vecchio et al. 2015).

Numerous authors such as Priestley (1997) and Calvi et al. (2002) suggested limiting the compression principal stresses $\left(p_{c}\right)$ such as average tensile principal stresses in tension. As per their experimental findings, the compression principal stresses $\left(p_{c}\right)$ must be restricted to values proportionate to the compressive strength of concrete as given in Equation (13).

$$
p_{c}=\frac{\sigma_{c}}{2} \cdot \sqrt{\left(\frac{\sigma_{c}}{2}\right)^{2}+v_{j h}^{2}} \leq 0.5 f_{c}
$$

Note: In some papers, $p_{t, t o t}^{\exp }$ is denoted by $f_{1}$. Likewise, $\sigma_{c}$ ([20]) is also denoted by $f_{a}$ ([19]) in some research articles.

$\sigma_{c}=F_{a}=$ axial compressive stress $=($ axial force $) /($ joint $\mathrm{x}$-area $)$.

(b) Principal compressive stress's direction, $\theta$ :

The equations suggested by [46] (also applied by [19,20] are used as given below:

i Constant direction:

$$
\theta=\text { const }=\operatorname{atan}\left(\frac{h_{b}}{h_{c}}\right)
$$

ii Varying direction:

$$
\theta^{\text {exp }}=\text { varying }=\frac{1}{2}\left[\pi-\operatorname{atan}\left(\frac{v_{j h}^{\exp }}{f_{a} / 2}\right)\right]
$$

where $f_{a}$ (also denoted as $\sigma_{c}$ ) $=$ axial stresses $=N / A_{\text {col }}$,

$v_{j h}^{\exp }=$ joint horizontal shear stress $=V_{j h} \exp ^{\operatorname{ex}} A_{\text {col }}$,

$N$ = axial load on column, and 


$$
A_{\text {col }}=\mathrm{X} \text {-area of column }=b_{c} \times h_{c}
$$

(c) Equivalent area of FRP, $\left(A_{f, e q}\right)$ :

The equivalent area of the FRP, $A_{f, e q}$, is calculated using the available simple equations for the most common applications of FRP sheets [19]. Equations (16)-(18) are used for calculating the area of continuous FRP sheets as given below:

Uniaxial fabric with fibers in the direction of beam axis $\left(0^{\circ}\right)$ or column axis $\left(90^{\circ}\right)$ :

$$
\left[\begin{array}{c}
A_{f, e q}=n_{l} \cdot n_{s} \cdot t_{f} \cdot h_{b} \cdot \sin \theta \text { for } \beta=0^{\circ} \\
A_{f, e q}=n_{l} \cdot n_{s} \cdot t_{f} \cdot h_{b} \cdot \cos \theta \text { for } \beta=90^{\circ}
\end{array}\right.
$$

Bidirectional fabric with fibers in the direction of beam and column axes $\left(0^{\circ}, 90^{\circ}\right)$ :

$$
A_{f, e q}=n_{l} \cdot n_{s} \cdot t_{f} \cdot h_{b} \cdot \cos \theta \cdot\left(1+\tan ^{2} \theta\right)
$$

Quadriaxial fabric with any fibers in the direction of beam $\left(0^{\circ}\right)$ and column $\left(90^{\circ}\right)$ axes and $\pm 45^{\circ}$ :

$$
A_{f, e q}=n_{l} \cdot n_{s} \cdot t_{f} \cdot h_{b} \cdot \cos \theta \cdot\left(1+\tan \theta+2 \tan ^{2} \theta\right)
$$

While Equations (19)-(21) are used for calculating the area of FRP strips or sheets for which angle of the fiber inclination is other than the $0^{\circ}, 45^{\circ}$, and $90^{\circ}$.

$$
A_{f, e q}=n_{l} \cdot n_{s} \cdot t_{f} \cdot b_{f}
$$

In the above equations, ns indicates the number of sides retrofitted with FRP for shear strengthening of the joint panel in the load plane (one or two sides), $n_{1}$ represents the layers' number of FRP applied on the strengthened side, $t_{f}$ is the corresponding thickness of the only dry fibers of the FRP, and $\mathrm{b}_{f}$ stands for FRP sheet's width, which may be computed using Equation (20), according to the angle of inclination of the fiber:

$$
\left[\begin{array}{ll}
b_{f}=h_{b} / \cos \beta & \text { for } \quad \beta<\theta \\
b_{f}=h_{b} / \sin \beta & \text { for } \quad \beta \geq \theta
\end{array}\right.
$$

For the discontinuous strips (partially wrapped with strips) of the FRP, Equation (21) may be used to calculate $b_{f}$ :

$$
\left[\begin{array}{l}
b_{f}=\left(w_{f} \cdot n_{s t r}\right)^{2} \cos \beta / h_{b} \quad \text { for } \quad \beta<\theta \\
b_{f}=\left(w_{f} \cdot n_{s t r}\right)^{2} \sin \beta / h_{c} \quad \text { for } \quad \beta \geq \theta
\end{array}\right.
$$

where $w_{f}$ is the width of each strip, $n_{s t r}$ is the number of strips in case of discontinuous strips (partially wrapped with strips), and $\beta$ is the inclination of the FRP fibers along with the beam axis. The area of each type (depending upon inclination of fibers) of FRP sheets/strips is calculated separately. The sum of all areas of all types of FRP is taken as equivalent FRP area, $A_{f, e q}$, for an assembly.

\subsection{The FRP and Joint Assembly Parameters}

The crucial parameters related to the FRP and joint assembly that can affect FRP strain need to be specified. In terms of the parameters, the equation of the effective FRP strain will be expressed. Similar parameters as those chosen by [19], including the parameters selected by [20], are selected for this purpose. The following parameters are selected based on the relation with the effective FRP strain of an assembly:
i. Concrete compressive strength, $f_{\mathrm{c}}$.
ii. Joint panel equivalent FRP area, $A_{f, e q}$
iii. Elastic modulus of the FRP fibers, $E_{f}$. 


\subsection{Drawing a Curve}

3.4.1. For the Principal Compressive Stress with Varying Direction $\left(\theta^{\exp }=\right.$ varying)

The product of the term $\left[\left(A_{f, e q} \cdot E_{f}\right) /\left(f_{c}^{2 / 3}\right)\right]$ on the X-axis and the effective FRP strain (on the Y-axis), computed via experimental data by using the varying direction of the principal compressive stress, is plotted as demonstrated in Figure 2.

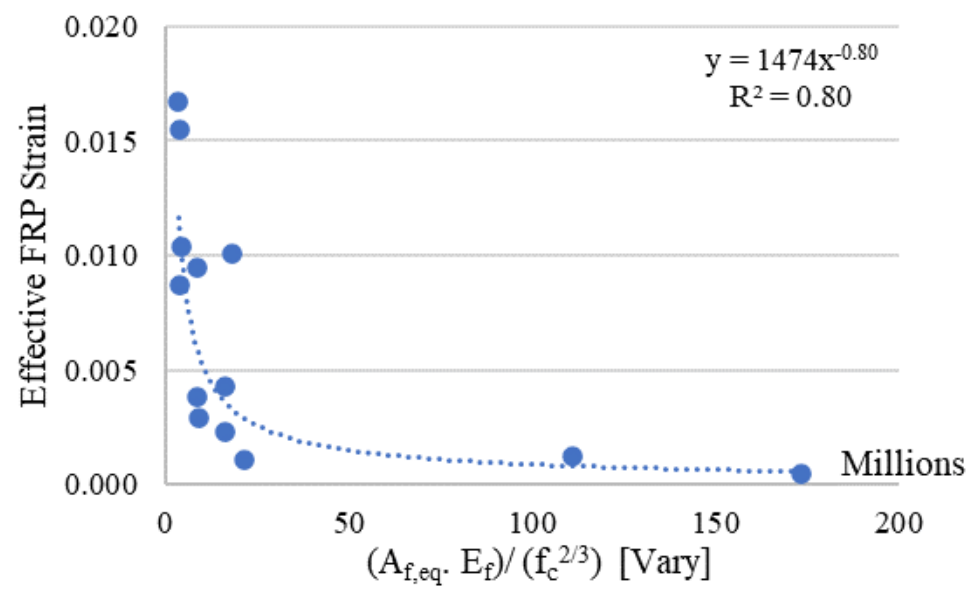

Figure 2. FRP strain for interior beam-column joint in terms of $\left(A_{f, e q} \cdot E_{f}\right) /\left(f_{c}^{2 / 3}\right)$ for $\theta_{\text {varying }}$.

3.4.2. For the Principal Compressive Stress with Constant Direction $\left(\theta^{e x p}=\right.$ constant)

The product of the term $\left[\left(A_{f, e q} \cdot E_{f}\right) /\left(f_{c}^{2 / 3}\right)\right]$ on the X-axis and the effective FRP strain computed via experimental data (on the Y-axis) by using the constant direction of the principal compressive stress is plotted as shown in Figure 3.

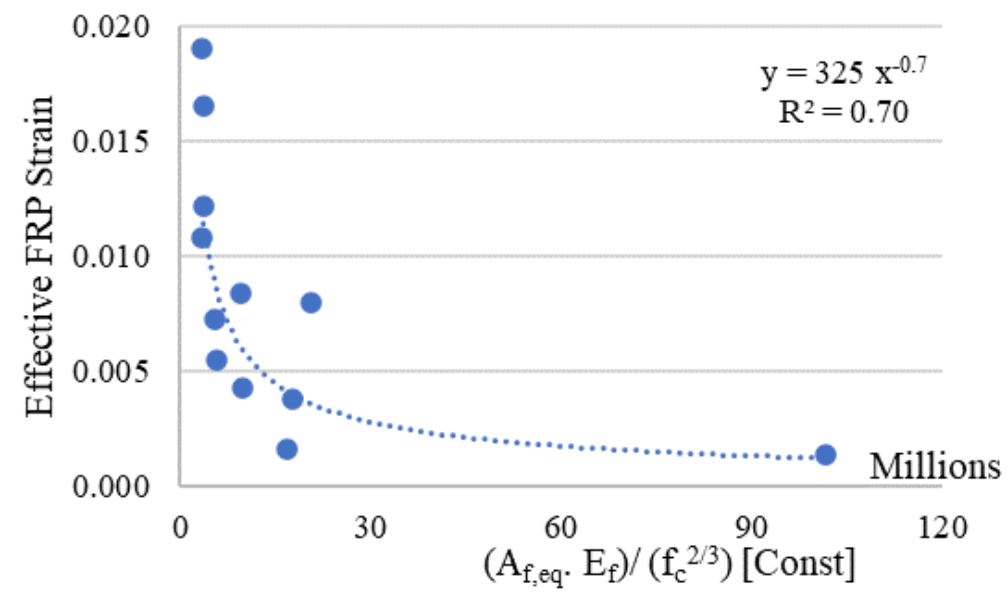

Figure 3. FRP strain for interior beam-column joint in terms of $\left(A_{f, e q} \cdot E_{f}\right) /\left(f c^{2 / 3}\right)$ for $\theta_{\text {constant }}$.

The equations for effective FRP strain resulting from both constant and varying directions of the principal compressive stress showed better results. The regression coefficients are equal to 0.70 and 0.80 for varying and constant directions of the principal compressive stress, respectively. It indicates that the equation of the effective FRP strain carries a high dependency on the factors considered in the regression model. This shows that the chosen parameters of the joint are better enough to express the effective FRP strain. By comparing the effectiveness and accuracy of both equations (one with $\theta_{\text {varying }}$ and the other with $\left.\theta_{\text {constant }}\right)$, the most feasible equation for the effective FRP strain is derived using the varying direction $\left(\theta_{\text {varying }}\right)$ of the principal compressive stress. The regression coefficient $\left(R^{2}\right)$ of 0.80 is noted for the effective FRP strain equation with varying direction $\left(\theta_{\text {varying }}\right)$ of the 
principal stress. Thus, the following equation is adopted with $R^{2}=0.80$ for calculating the effective FRP strain $\left(\varepsilon_{f, e}\right)$ :

$$
\varepsilon_{f, e}=1474 \cdot C_{I . D} \cdot C_{M . A}\left(\frac{f_{c}^{2 / 3}}{A_{f, e q} \cdot E_{f}}\right)^{0.80}
$$

\section{Validation of Model of Interior Joint}

The experimental findings for model calibration are equated with the analytic model calculations to evaluate the correctness of the suggested design method. The comparison of the analytical model for principal compressive stress with varying direction is given in Table 2. A good correlation is noted when the test results of the considered specimens are compared to those obtained using the proposed Equation (12) of the effective FRP strain $\left(\varepsilon_{f, e}\right)$ with $R^{2}=0.80$, using the varying direction of the principal compressive stress. As a result, the average ratio between the experimental and analytical (determined using the proposed model) joint shear strengths of the considered specimens is 0.98 . This ensures the accuracy of the suggested model to assess the shear strength of the FRP-strengthened under-designed interior joint.

Furthermore, the low values of coefficient of variation " $\mathrm{CoV}^{\prime}$ " $(0.24)$ and standard deviation "SD" (0.24) also support the accuracy of the proposed equation. Ultimately, the accuracy of the proposed equation of the effective FRP strain is also verified. Therefore, it can be concluded that the derived equation can effectively be used to determine the effective FRP strain of the FRP-strengthened interior BCJs.

The comparison of the experimental joint stress and that computed with the analytical model using the constant direction of the principal compressive stress is given in Table 3. Similar to the principal compressive stress with varying direction, a decent relationship is noted among the test results of the considered specimens and results of the proposed analytical model for the principal compressive stress with constant direction. The average ratio of experimental joint shear forces to analytical ones (calculated using the suggested model) for the investigated specimens is 0.92 . This assures the suggested model's correctness for evaluating the shear force of the FRP-strengthened under-designed interior joints. In addition, the small coefficient values of variation " $\mathrm{CoV}^{\prime}$ " $(0.22)$ and standard deviation "SD" (0.20) also confirm the precise nature of the suggested equation. Finally, the precision of the suggested FRP strain equation is checked. The resulting equation may be efficiently utilized to identify the effective FRP strain of the reinforced FRP internal BCJs. 
Table 2. Predicted shear stress of interior joint with the proposed model with $\theta_{\text {varying }}$.

\begin{tabular}{|c|c|c|c|c|c|c|c|c|c|c|c|c|c|c|c|c|c|c|}
\hline Test ID & $b_{c}$ & $h_{c}$ & $\sigma_{c}$ & $v_{\text {jhexp }}$ & $\theta($ Vary $)$ & $\theta$ (Vary) & $A_{f, e q}$ & $E_{f}$ & $E_{f}$ & $C_{I . D .}$ & $C_{M . A .}$ & $f_{c}$ & $f c^{(2 / 3)}$ & $e_{f e}$ & $P_{t, c}$ & $P_{t, f}$ & $v_{j h}$ & $v_{j h} / v_{j h \exp }$ \\
\hline- & $\mathrm{mm}$ & $\mathrm{mm}$ & MPa & MPa & $\mathrm{rad}$ & $\left(^{\circ}\right)$ & $\mathrm{mm}^{2}$ & GPa & $\mathrm{MPa}$ & - & - & MPa & - & $\mathrm{mm}$ & MPa & MPa & MPa & - \\
\hline PRO(L4) & 200 & 200 & 1.6 & 11.68 & 0.9 & 48.8 & 44 & 264.0 & 264,000 & 1 & 1 & 36.5 & 11.00 & 0.02240 & 1.75 & 4.89 & 7.40 & NA \\
\hline PRO(H4) & 200 & 200 & 3.1 & 14.55 & 0.9 & 51.1 & 42 & 264.0 & 264,000 & 1 & 1 & 39.8 & 11.66 & 0.02430 & 1.83 & 5.23 & 8.47 & NA \\
\hline AL-SA(IR1) & 160 & 300 & 3 & 6.46 & 1.0 & 57.5 & 588 & 61.5 & 61,500 & 0.8 & 1 & 30 & 9.65 & 0.00650 & 1.59 & 4.12 & 7.05 & 1.09 \\
\hline AL-SA(IS1) & 160 & 300 & 3 & 8.56 & 1.0 & 54.7 & 567 & 61.5 & 61,500 & 1 & 1 & 30 & 9.65 & 0.00840 & 1.59 & 4.96 & 7.91 & 0.92 \\
\hline AL-SA(IR2) & 160 & 300 & 1.6 & 6.73 & 0.9 & 51.6 & 546 & 61.5 & 61,500 & 0.8 & 1.5 & 25 & 8.55 & 0.00940 & 1.45 & 5.15 & 7.36 & 1.09 \\
\hline AL-SA(IS2) & 160 & 300 & 2.5 & 6.35 & 1.0 & 55.8 & 574 & 61.5 & 61,500 & 1 & 1.5 & 25 & 8.55 & 0.01130 & 1.45 & 6.86 & 9.48 & 1.49 \\
\hline PAN(R24-4) & 406 & 406 & 2.2 & 6.58 & 0.9 & 54.1 & 1913 & 106.0 & 106,000 & 1 & 1 & 43 & 12.27 & 0.00250 & 1.90 & 2.49 & 5.38 & 0.82 \\
\hline PAN(R16-2) & 406 & 406 & 2.2 & 5.32 & 1.0 & 56.0 & 1425 & 80.0 & 80,000 & 1 & 1 & 43 & 12.27 & 0.00390 & 1.90 & 2.24 & 5.12 & 0.96 \\
\hline PAN(R16-3) & 406 & 406 & 2.2 & 5.77 & 1.0 & 55.2 & 2532 & 43.0 & 43,000 & 1 & 1 & 43 & 12.27 & 0.00410 & 1.90 & 2.22 & 5.10 & 0.88 \\
\hline PAN(R16-4) & 406 & 406 & 2.2 & 6.01 & 1.0 & 54.9 & 1913 & 106.0 & 106,000 & 1 & 1 & 43 & 12.27 & 0.00250 & 1.90 & 2.51 & 5.40 & 0.90 \\
\hline Lee(JI2) & 400 & 400 & 1.4 & 8.01 & 0.9 & 49.8 & 630 & 258.0 & 258,000 & 1 & 1.5 & 27 & 9.00 & 0.00350 & 1.51 & 2.72 & 4.88 & 0.61 \\
\hline Allam (AR-2) & 254 & 406 & 1.7 & 4.32 & 1.0 & 55.9 & 1627 & 140.7 & 140,653 & 0.8 & 1 & 34.5 & 10.60 & 0.00160 & 1.70 & 2.94 & 5.42 & 1.25 \\
\hline Allam(RS-SC) & 254 & 406 & 1.7 & 9.75 & 0.9 & 50.0 & 8444 & 140.7 & 140,653 & 1 & 1 & 34.5 & 10.60 & 0.00050 & 1.70 & 4.41 & 6.91 & 0.71 \\
\hline Allam(RS-G) & 254 & 406 & 1.7 & 8.99 & 0.9 & 50.4 & 2004 & 26.2 & 26,200 & 1 & 1 & 34.5 & 10.60 & 0.00650 & 1.70 & 2.55 & 5.03 & NA \\
\hline Attari(NR2) & 100 & 150 & 3.30 & 14.33 & 0.9 & 51.6 & 936 & 19.2 & 19,200 & 1 & 1 & 39 & 11.50 & 0.01630 & 1.81 & 15.30 & 18.69 & 1.30 \\
\hline
\end{tabular}

Average $=0.98, \mathrm{SD}=0.24, \mathrm{CoV}=0.24$. NA are specimens that have shown an adjacent members' bending failure $(\mathrm{BH}$ or $\mathrm{CH})$, and the ratio is not calculated. 
Table 3. Predicted shear stress of interior joint with the proposed model with $\theta_{\text {constant }}$.

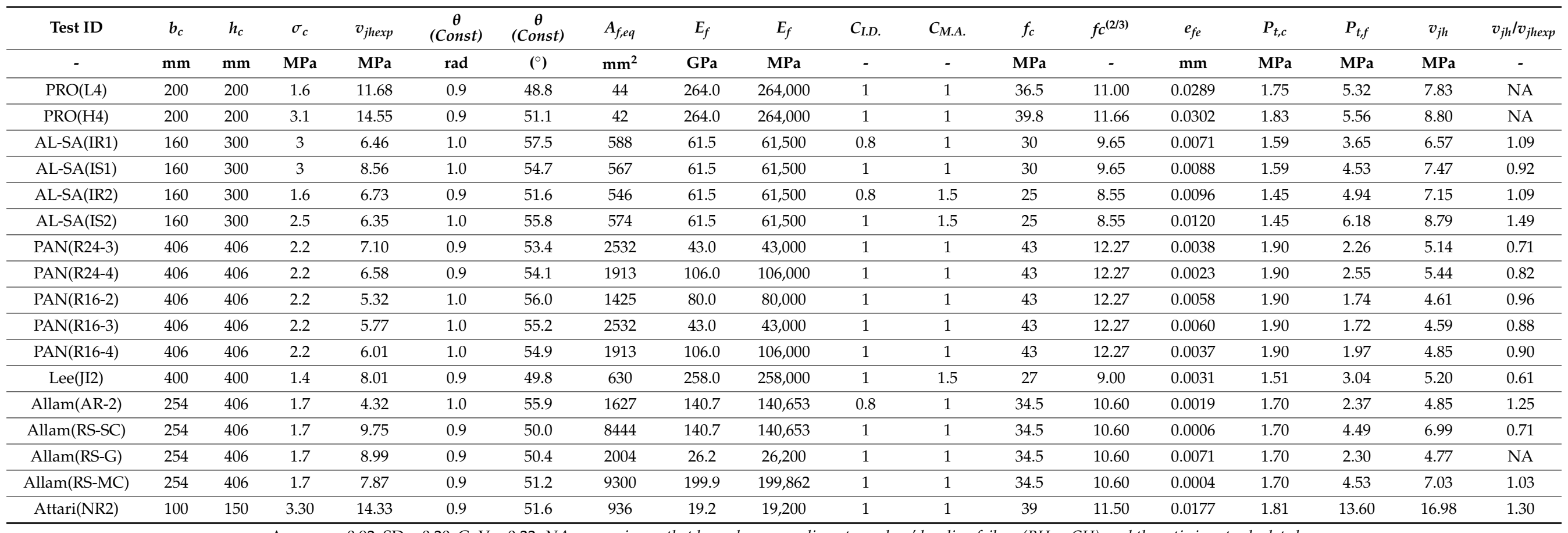

Average $=0.92, \mathrm{SD}=0.20, \mathrm{CoV}=0.22$. NA are specimens that have shown an adjacent members' bending failure (BH or $\mathrm{CH}$ ), and the ratio is not calculated. 
For further verification and confirmation of the validity and accuracy of the equation, the joint shear stresses of the specimens calculated by using the proposed analytical model are compared with that of the experimentally determined joint shear stresses, as demonstrated in Figure 4.

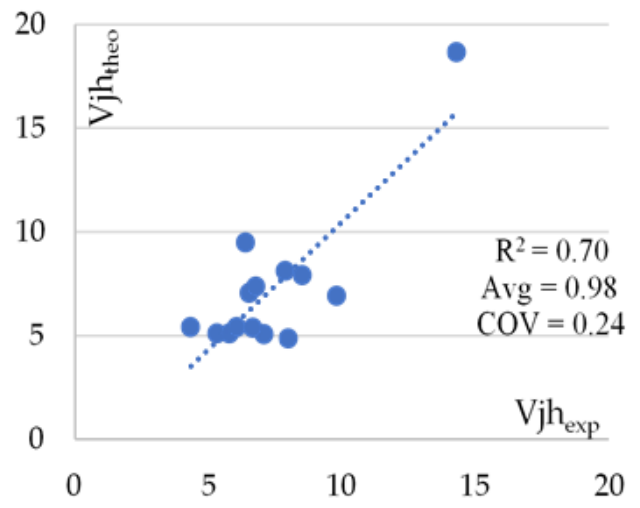

(a) for the varying direction of principal stress

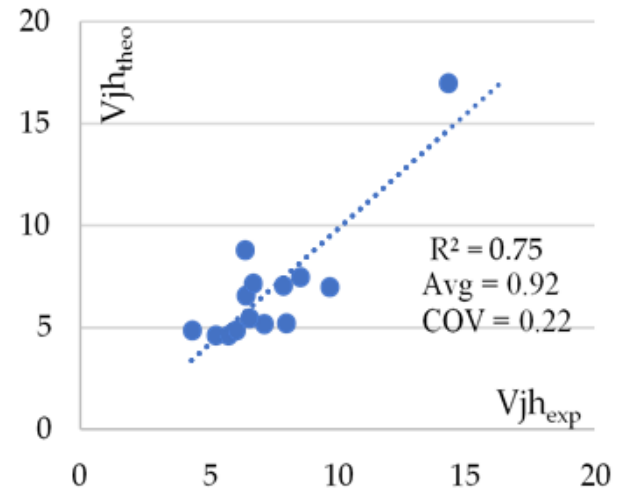

(b) for the constant direction of principal stress

Figure 4. Comparison of experimental and predicted results in terms of joint shear stress.

A better coherence is shown with high similarity among the experimental and predicted results. The joint stresses were determined using the proposed analytical model for two different directions, i.e., varying and constant of the principal compressive stresses. A moderate $R$ factor $\left(R^{2}\right)$ of equal to or more than 0.70 is noted for both directions of the principal compressive stress, verifying the model's precision. Similarly, the mean of ratios of the predicated and experimental joint shear stresses is found to be 0.98 , with a low coefficient of variation (COV) of 0.24 for the varying direction of principal stress and 0.92 with 0.22 of COV for the constant direction of principal stress. The decent average (near to one) of the ratios also supports the satisfactory accuracy of the proposed equation in assessing the joint shear stress.

Similarly, the contribution of FRP to the interior joint's compression strength is compared with that of the experimentally calculated to check the accuracy of the analytical model in assessing the contribution of the FRP. The contribution of the FRP is calculated by using both directions (varying and constant) of the principal compressive stress of the joint. The comparison of the experimentally and analytically calculated FRP contributions is shown in Figure 5.

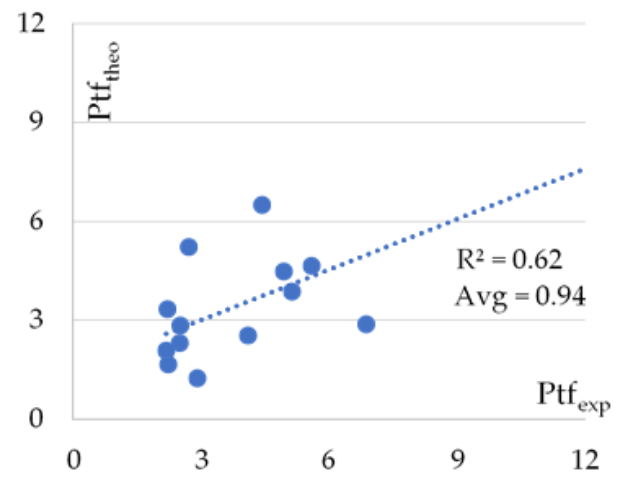

(a) for the varying direction of principal stress

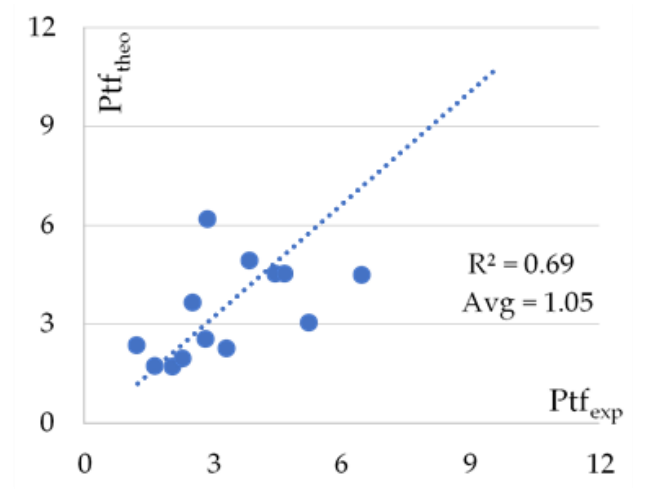

(b) for the constant direction of principal stress

Figure 5. Comparison of experimental and predicted results in terms of FRP contribution. 
Such as the substantial similarity between the predicated and experimental joint shear stresses, better coherence is noted between the predicated and experimental contribution of the FRP to the shear strength of the joint. In addition, the coefficient of regression is more than $60 \%$ for both directions of the principal compressive stresses of the joint.

Similarly, the averages of the ratios of the experimentally and analytically calculated contribution of the FRP to joint shear strength are 0.94 and 1.05 for varying and constant directions of principal stress, respectively. Thus, both the moderate $R$ factor $\left(R^{2}\right)$ and the reliable mean of the ratios confirm the accuracy of the suggested analytical model to predict the contribution of the FRP to the shear strength of the interior joint. Furthermore, this guarantees the capability of the proposed equation to assess the actual contribution of the FRP to the shear strength of the joint.

\section{Discussion and Conclusions}

This study discussed the use of FRP for strengthening non-seismic RC interior beam-column joints (BCJs) in shear, which constitute the essential components of the present RC building. In addition, the efficiency of the FRP materials in strengthening non-seismic interior beam-column connections was greatly established. However, an accurate and straightforward equation is still required to estimate an increase in the shear strength of the deficient interior beam-column joints due to FRP strengthening. A literature review was carried out to identify significant parameters that affect the externally bound FRP system's mechanical behavior. The research focused directly or indirectly on the parameters that impact the mechanical characteristics of the externally bonded systems of FRP. In addition, the available analytical models were critically evaluated and discussed. The procedure outlined by $[19,20]$ for corner and external beam-column joints was followed. A reliable and straightforward analytical model was outlined in compliance with the available updated test data. The predicted results of the suggested model were compared and verified with the experimental test database. The model was based on the primary approach to principal tensile stress. The debonding phenomenon was considered in the expression for the effective FRP strain and was calibrated on experimental tests. An illustrative example of utilizing the suggested model for calculating the shear strength of the FRP-strengthened interior deficient BCJ is given in Appendix A. The use of the proposed equation to calculate the number of fibers required to fulfill the deficiency in shear strength of the beam-column joint due to the absence of seismic reinforcement is also explained.

The suggested formulation is compatible with experimental results in terms of the mean effective stress. The derived equation permits the FRP strain limited to $0.4 \%$ to be exceeded, as usually anticipated in the guidelines of the existing building design. The suggested design method was calibrated by experimental test results of interior beamcolumn joints with geometric attributes and mechanical parameters characteristic of RC structures exposed to large earthquakes. It enables to determine the shear strength of the non-seismic interior beam-column joints reinforced with various types of fiber (CFRPs and GFRPs), various fiber reinforcement arrangements on the joint panel with a flexible amount of fiber, layer numbers, side numbers, the fiber inclination (or multiple inclined fibers), continuous strips and sheets, damaged and lightly repaired joints with FRP system, and the effect of the various types of anchorage systems to enhance the effectiveness of the fiber in strengthening. The following conclusions can be drawn:

- The available experimental tests related to deficient interior $\mathrm{RC}$ beam-column joints were explored, out of which 17 specimens were applicable to be used.

- The corner and exterior joints-oriented method outlined by [20], later refined by [19], was extended to formulate a simple analytical model for non-seismic RC interior beam-column joints. 
- A reliable equation for effective FRP strain was derived. The equation was calibrated and verified by using the available experimental test data. The FRP strain showed a maximum dependency on the joint parameters of which the equation was formed. The regression coefficient $\left(R^{2}\right)$ was 0.80 , showing a better relationship between the considered parameters and the FRP strain.

- The proposed equation was very efficient in predicting the FRP's contribution to the joint's shear strength. The difference in the average ratio of the experimental and shear strength of the joint calculated with the suggested method was less than $1 \%$ for principal compressive stress in each direction.

- Enhancement in the shear strength of the joint due to FRP was predicted very well compared to that of the experimental results of the same specimen. Thus, the difference of average ratio of the experimental and predicted FRP contribution to the shear strength of the joint was less than $1 \%$, supporting the trustworthiness of the proposed method.

The suggested approach makes quantifying the FRP enhancements required to avoid shear failure in interior joints easy and reliable for researchers and field engineers interested in seismically reinforcing existing structures. However, as the mechanical behavior of the subassemblies with significant slips of reinforcement inside the joint panel (that is, smooth bars reinforced beam-column joints), the suggested model needs to be further refined on the availability of sufficient test data. Therefore, the proposed model must be further refined. Furthermore, the slab's influence must be considered for adopting the shear strengthening procedure/technique for any type of RC beam-column joints.

Author Contributions: Conceptualization, A.Z.; methodology, A.Z.; validation, A.Z.; formal analysis, A.Z.; investigation, A.Z.; resources, A.Z. and Z.P.; data curation, A.Z.; writing-original draft preparation, A.Z.; writing-review and editing, A.Z., T.U., M.A.U.R.T.: visualization, A.Z.; supervision, Z.P., I.H.; project administration, A.Z. and Z.P. All authors have read and agreed to the published version of the manuscript.

Funding: This research received no external funding. The APC was funded by "Zhang Pu".

Institutional Review Board Statement: Not applicable.

Data Availability Statement: Not applicable.

Acknowledgments: The authors would like to extend their acknowledgments to all individuals who helped them throughout the research work. The authors also acknowledge the financial support from the National Natural Science Foundation of China (U1904177), National Natural Science Foundation of China (52108183), the Excellent Youth Foundation of Henan Province of China (212300410079), and the Project of Young Key Teachers in Henan Province of China (2019GGJS01).

Conflicts of Interest: The authors declare no conflict of interest.

\section{Nomenclature}

$A_{\text {col }} \quad$ Cross-section area of column

$A_{f, e q} \quad$ Equivalent area of FRP area on the joint

$b_{c} \quad$ Width of column

$b_{f} \quad$ Width of the FRP sheet

$C_{I . D .} \quad$ Initial damage's numerical coefficient

$C_{A . M .} \quad$ Mechanical anchorage's numerical coefficient

$d_{b} \quad$ Internal lever arm of beam

$E_{f} \quad$ Modulus of elasticity of FRP fibers

$f_{a} \quad$ Axial stress of column

$f_{c} \quad$ Mean cylinder compressive strength of concrete

$h_{b} \quad$ Height of beam

$h_{c} \quad$ Height of column 
jd Distance from the tension and compression resultants in the beam at the beam joint interface

$l_{b} \quad$ Length of beam measured from the column face

$l_{c} \quad$ Entire test set-up height (i.e., from the bottom column pin to the top column pin)

$M_{b 1} \quad$ Bending moment of beam due to $P_{b 1}$

$M_{b i} \quad$ Moment in the beam at the beam-joint interface

$N \quad$ Axial load on column

$n_{S} \quad$ Number of sides of joint strengthened with FRP systems in shear in the line of action of load

$n_{l} \quad$ Number of FRP layers

$n_{\text {str }} \quad$ Number of strips on the joint panel

$P_{b 1} \quad$ Maximum tip load at the end of the beam taken from experimental test results

$p_{c} \quad$ Principal compression stress of joint core

$p_{t} \quad$ Joint panel principal tensile stress

$P_{t, c} \quad$ Contribution of concrete to principal tensile stress of joint core

$P_{c} \quad$ Maximum tip load at the end of the column taken from Experimental test results

$p_{t, f} \quad$ FRP contribution to joint panel principal tensile stress

$P_{t, t o t} \quad$ Joint panel total principal tensile stress

$t_{f} \quad$ Equivalent thickness of the FRP reinforcement (dry fibers only)

$T_{s 1}, T_{s 2} \quad$ Forces in the longitudinal steel of the beam

$T_{f, i} \quad$ Total force of FRP fibers in the generic direction

$V_{b} \quad$ Beam shear

$V_{c} \quad$ Column shear

$V_{j h} \quad$ Horizontal joint shear

$v_{j h} \quad$ Horizontal joint shear stress

$V_{\text {col }} \quad$ Shear force in column

$V_{j v} \quad$ Vertical joint shear

$w_{f} \quad$ Strip width

$b \quad$ Inclination of joint panel FRP fibers

$W_{b} \quad$ Whole set-up width

$e_{f, e} \quad$ Effective FRP strain

$\theta \quad$ Angle corresponding to concrete's compressive strut, considered equal to joint cracks' inclination

$\theta_{\text {varying }} \quad$ Varying direction of the principal compressive stress

$\theta_{\text {constant }}$ Constant direction of the principal compressive stress

$v_{j h}^{\text {exp }} \quad$ Experimental joint horizontal shear stress

$\beta \quad$ Inclination of fibers with beam axis

$\sigma_{c} \quad$ Axial compressive stress

$\varepsilon_{f, e}^{e x p} \quad$ Effective FRP strain from experimental data

$\theta^{\exp } \quad$ Experimentally determined principal compressive stress inclination

\section{Appendix A. Solved Example}

Attari [12] tested 1/3-scale reinforced concrete interior beam-column joint specimen (NC1). The specimen and reinforcement used are detailed in Figure A1. The length of each beam from the face of the column, $l_{b i}$ (i.e., $l_{b 1}$ and $l_{b 2}$ ) was $600 \mathrm{~mm}$, and the total length of the beam was $1350 \mathrm{~mm}$ between the point of loading. The total length of the column, $l_{c}$, was $800 \mathrm{~mm}$. Four longitudinal steel bars of $8 \mathrm{~mm}$ diameter were used for both the beam and the column. Steel stirrups, $6 \mathrm{~mm}$ in diameter, spaced at $100 \mathrm{~mm}$ intervals, were used as shear reinforcement. The beams and the column had a rectangular cross-section of $100 \times$ $150 \mathrm{~mm}$ with $h_{c}=h_{b}=150 \mathrm{~mm}$ and $b_{b}=b_{c}=100 \mathrm{~mm}$. 


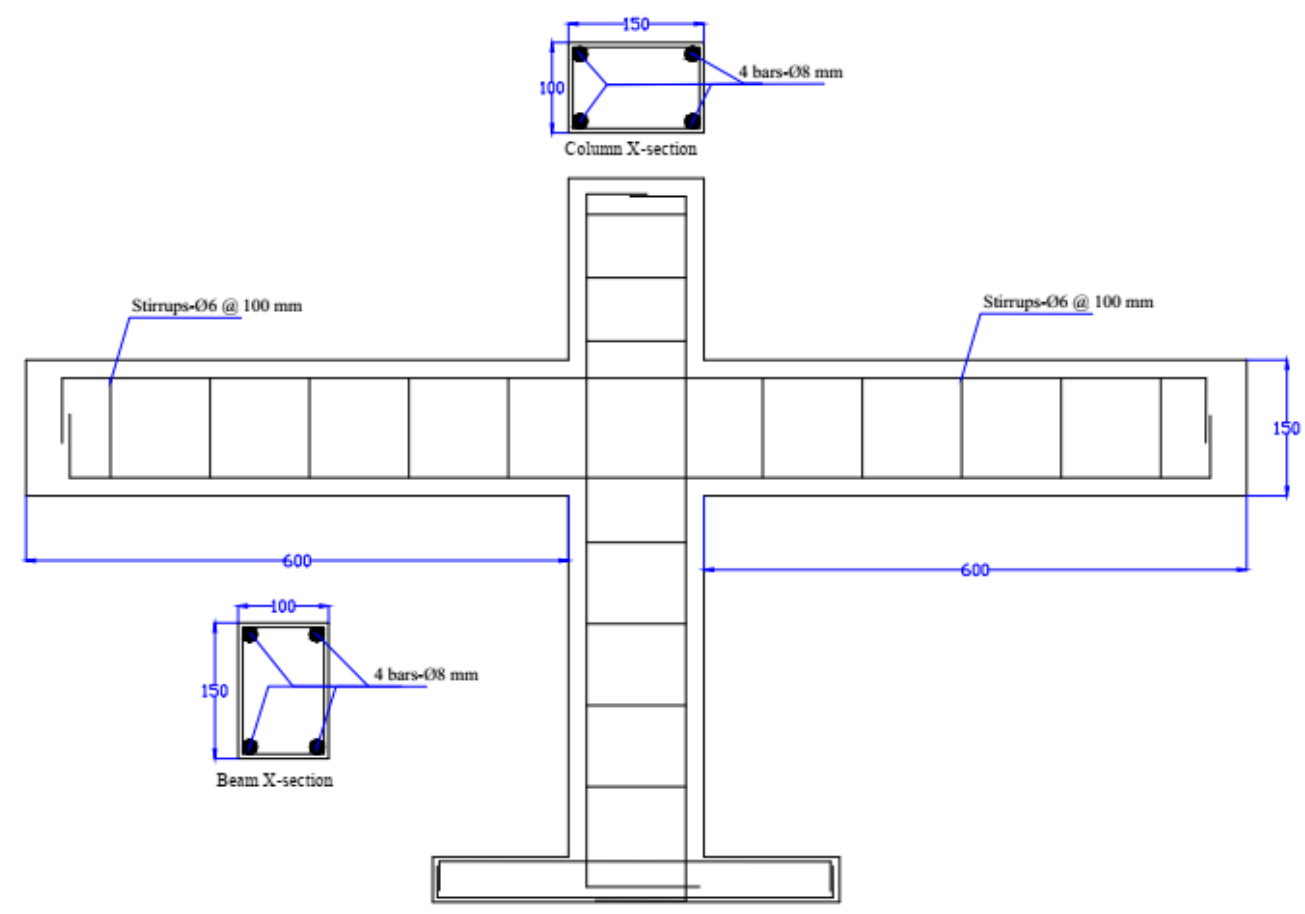

Figure A1. Geometrical details of the NCI [12].

The concrete cylinder's average compressive strength was $39 \mathrm{MPa}$. The yield strength of the tensile, shear, and compression reinforcing bars was about $500 \mathrm{MPa}$. All beams were subjected to cyclic reverse loading. The column was loaded with a steady axial load of $100 \mathrm{kN}$. The joint panel was deficient in transverse reinforcement, which resulted in a premature shear failure; as a result, the structural system's seismic performance was adversely affected. To make possible further ductile flexural failure and prevent shear failure, the proposed approach is used to determine the correct quantity of FRP fibers for the joint panel.

By using the principal stress approach Equation (11), the shear stress capacity of the as-built joint, $v_{j h}$, may be calculated as given below:

$$
\begin{gathered}
p_{t, t o t}^{\exp }=\frac{-\sigma_{c}}{2}+\sqrt{\left(\frac{-\sigma_{c}}{2}\right)^{2}+v_{j h}{ }^{2}} \\
v_{j h}=p_{t, t o t} \cdot \sqrt{1+\left(\frac{\sigma_{c}}{P_{t, t o t}}\right)}
\end{gathered}
$$

Considering $p_{t, t o t}$ is equal to $p_{t, c}$, and $p_{t, c}$ can be computed by Equation (12). $p_{t, c}=$ $0.29(f c)^{0.5}=0.29(39)^{0.5}=1.81 \mathrm{MPa}$. Where $\sigma_{c}=f_{a}=$ axial stress $=$ Axial load $/$ Acol $=\frac{N}{b c \cdot h c}$

$$
\begin{aligned}
& \sigma_{c}=\frac{\mathrm{N}}{b_{c} \cdot h_{c}}=\frac{100,000}{(100) \cdot(150)}=6.67 \mathrm{MPa} \\
& v_{j h}^{d}=1.81+\sqrt{1+\left(\frac{6.67}{1.81}\right)}=3.97 \mathrm{MPa}
\end{aligned}
$$

The design shear stress $v_{j h}^{d}$ is the joint shear stress related to the flexural yielding of the weaker beam and column, representing the goal value for the design of the FRP strengthening. This conforms to an approach for capacity design. Here in the considered case, the initial yielding of the specimen corresponds to the beam yielding matching to the $v_{j h}^{d}=7.53 \mathrm{MPa}$ joint shear stress calculated with Equation (8). Due to the shear strength (3.97 
$\mathrm{MPa}$ ) being $52.7 \%$ of the design value of the as-built joint, strengthening the joint panel with FRP is necessary (i.e., 47.3 percent increase is required in the actual shear capacity).

In this example, the joint panel of uniaxial GFRP fabric with fibers inclined at $0^{\circ}$ at the axis of the beam is supposed to be strengthened with one layer $\left(n_{1}=1\right)$. The modulus of elasticity, $E_{f}$, is taken as 19.2 GPa. Dry fiber thickness, $t f$, in each direction is approximately $2 \mathrm{~mm}$. Due to the absence of orthogonal beams to the load plane, shear strengthening of the joint panel can be carried on both sides $\left(n_{S}=2\right)$.

At maximum capacity, the inclination of the crack, $\theta$, may be calculated by Equation (14) to determine the FRP system's equivalent area by Equation (16).

$$
\begin{gathered}
\theta=\text { const }=\operatorname{atan}\left(\frac{h_{b}}{h_{c}}\right)=\operatorname{atan}\left(\frac{150}{150}\right)=45^{\circ} \\
A_{f, e q}=n_{l} \cdot n_{s} \cdot t_{f} \cdot h_{b} \cdot \sin \theta \text { for } \beta=0^{\circ} \\
A_{f, e q}=1 \cdot 2 \cdot 2 \cdot 150 \cdot \sin \left(45^{\circ}\right)=424.26 \mathrm{~mm}^{2}
\end{gathered}
$$

The effective FRP strain may be estimated by Equation (22) after the equivalent FRP area is known without assuming the joint panel's starting damage $\left(C_{I . D .}=1\right)$. Bonding conditions of the FRP system at the ends $\left(C_{M . A .}=1\right)$ are not enhanced through mechanical anchoring.

$$
\begin{gathered}
\varepsilon_{f, e}=1474 \cdot C_{I . D} \cdot C_{M . A}\left(\frac{f_{c}^{\frac{2}{3}}}{A_{f, e q} \cdot E_{f}}\right)^{0.80} \\
\varepsilon_{f, e}=1474 \cdot 1 \cdot 1 \cdot\left(\frac{(39)^{2 / 3}}{(424.26) \cdot(19500)}\right)^{0.80}=0.030
\end{gathered}
$$

Equation (9) may be used to calculate the contribution of the FRP system to the principal tensile stress:

$$
\begin{gathered}
\varepsilon_{f, e}^{\exp }=\frac{\mathrm{p}_{t, f}^{\exp } \cdot b_{c} \cdot \mathrm{h}_{c}}{A_{f, e q} \cdot E_{f} \cdot \sin \theta} \\
p_{t, f}=\frac{\varepsilon_{f, e} \cdot A_{f, e q} \cdot E_{f}}{b_{c} \cdot \frac{\mathrm{h}_{c}}{\sin \theta}}=\frac{0.030 \cdot(424.26) \cdot 19500}{100 \cdot \frac{150}{\sin (45)}}=11.69 \mathrm{MPa}
\end{gathered}
$$

The sum of concrete contribution, $P_{t, c}$, and the FRP contribution, $P_{t, f}$, can be used to determine the total resisting principal tensile stress Equation (10):

$$
\begin{gathered}
p_{t, f}^{\exp }=\left(p_{t, t o t}^{\exp }\right)-\left(p_{t, c}\right) \\
\Rightarrow p_{t, t o t}=p_{t, f}+p_{t, c}=11.69+1.81=13.5 \mathrm{MPa}
\end{gathered}
$$

By strengthening with the chosen FRP system, the joint panel's shear strength can be computed by replacing again in Equation (11):

$$
\begin{gathered}
v_{j h}=P_{t, t o t} \cdot \sqrt{1+\left(\frac{\sigma_{c}}{P_{t, t o t}}\right)}=v_{j h}=P_{t, t o t} \cdot \sqrt{1+\left(\frac{N /(h c \cdot b c)}{P_{t, t o t}}\right)} \\
v_{j h}=13.5+\sqrt{1+\left(\frac{150,000 /(150 \cdot 100)}{13.5}\right)}=14.81 \mathrm{MPa}
\end{gathered}
$$

Shear strength $v_{j h}$ is greater than the design shear strength, $v_{j h}^{d}=7.53 \mathrm{MPa}$. The crushing of compressive concrete strut $\left(p_{c}>v_{j h}\right)$ must be checked to verify the joint capacity. Using Equation (12), the compression capacity of the joint panel is calculated. 
Where $p_{c}=v_{j h}^{c}=0.5\left(f_{c}\right)$ and is equivalent to $v_{j h}^{c}=19.5 \mathrm{MPa}$, it is significantly greater than $v_{j h}(=14.81 \mathrm{MPa})$.

With a single uniaxial GFRP sheet, the suggested reinforcement method improves the joint shear capacity by around 73 percent. In addition, the FRP shear strengthening design avoids a shear failure on the joint panel, which ensures that the column failed in the plastic hinge and ductile model of failure is attained instead of the brittle one.

\section{References}

1. Alva, G.M.S.; de Cresce El Debs, A.L.H.; El Debs, M.K. An experimental study on cyclic behaviour of reinforced concrete connections. Can. J. Civ. Eng. 2007, 34, 565-575. [CrossRef]

2. Engindeniz, M.; Kahn, L.F.; Abdul-Hamid, Z. Repair and Strengthening of Reinforced Concrete Beam-Column Joints: State of the Art. ACI Struct. J. 2005, 102, 1. [CrossRef]

3. Liu, C. Seismic Behaviour of Beam-Column Joint Subassemblies Reinforced with Steel Fibres. Ph.D. Theisis, University of Canterbury, Christchurch, New Zealand, 2006.

4. Karayannis, C.G.; Chalioris, C.E.; Sirkelis, G.M. Local retrofit of exterior RC beam-column joints using thin RC jackets-An experimental study. Earthq. Eng. Struct. Dyn. 2007, 37, 727-746. [CrossRef]

5. Lam, E.S.-S.; Li, B.; Xue, Z.-H.; Leung, K.-T.; Lam, J.Y.-K. Experimental studies on reinforced concrete interior beam-column joints strengthened by unsymmetrical chamfers. Eng. Struct. 2019, 191, 575-582. [CrossRef]

6. Del Vecchio, C.; Di Ludovico, M.; Balsamo, A.; Prota, A. Seismic Retrofit of Real Beam-Column Joints Using Fiber-Reinforced Cement Composites. J. Struct. Eng. 2018, 144, 04018026. [CrossRef]

7. Sharma, R.; Bansal, P.P. Behavior of RC exterior beam column joint retrofitted using UHP-HFRC. Constr. Build. Mater. 2018, 195, 376-389. [CrossRef]

8. Alhaddad, M.S.; Binyahya, A.S.; Alrubaidi, M.; Abadel, A.A. Seismic performance of R.C buildings with Beam-Column joints upgraded using FRP laminates. J. King Saud Univ. Eng. Sci. 2020, 33, 386-395. [CrossRef]

9. Golias, E.; Zapris, A.; Kytinou, V.; Kalogeropoulos, G.; Chalioris, C.; Karayannis, C. Effectiveness of the Novel Rehabilitation Method of Seismically Damaged RC Joints Using C-FRP Ropes and Comparison with Widely Applied Method Using C-FRP Sheets-Experimental Investigation. Sustainability 2021, 13, 6454. [CrossRef]

10. Majumder, S.; Saha, S. Quasi-static cyclic performance of RC exterior beam-column joint assemblages strengthened with geosynthetic materials. Structures 2020, 29, 1210-1228. [CrossRef]

11. De Risi, M.T.; Del Vecchio, C.; Ricci, P.; Di Ludovico, M.; Prota, A.; Verderame, G.M. Light FRP Strengthening of Poorly Detailed Reinforced Concrete Exterior Beam-Column Joints. J. Compos. Constr. 2020, 24, 04020014. [CrossRef]

12. Attari, N.; Youcef, Y.S.; Amziane, S. Seismic performance of reinforced concrete beam-column joint strengthening by frp sheets. Structures 2019, 20, 353-364. [CrossRef]

13. Wang, G.-L.; Dai, J.-G.; Bai, Y.-L. Seismic retrofit of exterior RC beam-column joints with bonded CFRP reinforcement: An experimental study. Compos. Struct. 2019, 224, 111018. [CrossRef]

14. Pichandi, S.; Rana, S.; Oliveira, D.; Fangueiro, R. Fibrous and composite materials for blast protection of structural elements-A state-of-the-art review. J. Reinf. Plast. Compos. 2013, 32, 1477-1500. [CrossRef]

15. Buchan, P.; Chen, J.-F. Blast resistance of FRP composites and polymer strengthened concrete and masonry structures-A state-of-the-art review. Compos. Part B: Eng. 2007, 38, 509-522. [CrossRef]

16. Balsamo, A.; Di Ludovico, M.; Lignola, G.P.; Prota, A.; Manfredi, G.; Cosenza, E. Composites for Structural Strengthening. In Wiley Encyclopedia of Composites; John Wiley \& Sons, Inc.: Hoboken, NJ, USA, 2012.

17. Pohoryles, D.A.; Melo, J.; Rossetto, T. Numerical Modelling of FRP-Strengthened RC Beam-Column Joints. In Proceedings of the 2015 SECED Conference: Earthquake Risk and Engineering towards a Resilient World, Cambridge, UK, 9-10 July 2015.

18. Goswami, A.; Das Adhikary, S. Retrofitting materials for enhanced blast performance of Structures: Recent advancement and challenges ahead. Constr. Build. Mater. 2019, 204, 224-243. [CrossRef]

19. Del Vecchio, C.; Di Ludovico, M.; Prota, A.; Manfredi, G. Analytical model and design approach for FRP strengthening of non-conforming RC corner beam-column joints. Eng. Struct. 2015, 87, 8-20. [CrossRef]

20. Bousselham, A. State of Research on Seismic Retrofit of RC Beam-Column Joints with Externally Bonded FRP. J. Compos. Constr. 2010, 14, 49-61. [CrossRef]

21. American Concrete Institute. ACI 440.2R-08, Guide for the Design and Construction of Externally Bonded FRP Systems for Strengthening Existing Structures; American Concrete Institute: Farmington Hills, MI, USA, 2008.

22. Standard, C.S.A. S806-02 Design and Construction of Building Components with Fibre-Reinforced Polymers; Canadian Standards Association: Toronto, ON, Canada, 2002.

23. Balázs, G.L.; Cox, B.; Fardis, M.; Forbes, J.; Jirsa, J.; Kumar, V.; Monti, G.; Ozaka, Y.; Shehata, L.; Siviero, E.; et al. Retrofitting of concrete structures by externally bonded FRPs with emphasis on seismic applications. Bulletin 2006, 35. [CrossRef] 
24. (National Research Council) CNR. Guide for the Design and Construction of Externally Bonded FRP Systems for Strengthening Existing Structures: Materials, RC and PC Structures, Masonry Structures CNR-DT 200 R1/2013; CNR: Roma, Italy, 2013.

25. Pantazopoulou, S.; Bonacci, J. Consideration of Questions about Beam-Column Joints. ACI Struct. J. 1993, 89, 27-36. [CrossRef]

26. Antonopoulos, C.P.; Triantafillou, T. Analysis of FRP-Strengthened RC Beam-Column Joints. J. Compos. Constr. 2002, 6, 41-51. [CrossRef]

27. Almusallam, T.H.; Al-Salloum, Y.A. Seismic Response of Interior RC Beam-Column Joints Upgraded with FRP Sheets. II: Analysis and Parametric Study. J. Compos. Constr. 2007, 11, 590-600. [CrossRef]

28. Tsonos, A.G. Effectiveness of CFRP-jackets and RC-jackets in post-earthquake and pre-earthquake retrofitting of beam-column subassemblages. Eng. Struct. 2008, 30, 777-793. [CrossRef]

29. Cheung, P.C.; Paulay, T.; Park, R. Behavior of beam-column joints in seismically-loaded RC frames. Struct. Eng. 1993, 71, 129.

30. Del Vecchio, C.; Di Ludovico, M.; Balsamo, A.; Prota, A.; Manfredi, G.; Dolce, M. Experimental Investigation of Exterior RC Beam-Column Joints Retrofitted with FRP Systems. J. Compos. Constr. 2014, 18, 04014002. [CrossRef]

31. Okahashi, Y.; Pantelides, C.P. Strut-and-tie model for interior RC beam-column joints with substandard details retrofitted with CFRP jackets. Compos. Struct. 2017, 165, 1-8. [CrossRef]

32. Akguzel, U.; Pampanin, S. Recent Developments in Seismic Strengthening of RC Beam-Column Joints with FRP Materials. In Proceedings of the 15th World Conference on Earthquake Engineering, Lisbon, Portugal, 24-28 September 2012.

33. Tasligedik, A.S. Capacity estimation of FRP strengthened RC beam-column joints using hierarchy of strength assessment. Bull. Earthq. Eng. 2017, 16, 1323-1340. [CrossRef]

34. Holzenkämpfer, P. Ingenieurmodelle des Verbunds Geklebter Bewehrung für Betonbauteile; Technical University of BraunschweigMaterials Testing Institute for the Building Industry; IBMB: Braunschweig, Germany; MPA: Braunschweig, Germany, 1994.

35. Triantafillou, T.; Matthys, S.; Audenaert, K.; Balázs, G.; Blaschko, M.; Blontrock, H.; Czaderski, C.; David, E.; Di Tomasso, A.; Duckett, W.; et al. Externally bonded FRP reinforcement for RC structures. Bulletin FIB 2001, 14. [CrossRef]

36. Kibria, B.M.G.; Ahmed, F.; Ahsan, R.; Ansary, M.A. Experimental investigation on behavior of reinforced concrete interior beam column joints retrofitted with fiber reinforced polymers. Asian J. Civ. Eng. 2019, 21, 157-171. [CrossRef]

37. Lee, W.; Chiou, Y.; Shih, M. Reinforced concrete beam-column joint strengthened with carbon fiber reinforced polymer. Compos. Struct. 2010, 92, 48-60. [CrossRef]

38. Ma, C.; Wang, D.; Wang, Z. Seismic retrofitting of full-scale RC interior beam-column-slab subassemblies with CFRP wraps Compos. Struct. 2017, 159, 397-409. [CrossRef]

39. Prota, A.; Nanni, A.; Manfredi, G.; Cosenza, E. Selective Upgrade of Underdesigned Reinforced Concrete Beam-Column Joints Using Carbon Fiber-Reinforced Polymers. ACI Struct. J. 2004, 101. [CrossRef]

40. Pantelides, C.P.; Okahashi, Y.; Reaveley, L.D. Seismic Rehabilitation of Reinforced Concrete Frame Interior Beam-Column Joints with FRP Composites. J. Compos. Constr. 2008, 12, 435-445. [CrossRef]

41. Allam, K.; Mosallam, A.S.; Salama, M.A. Experimental evaluation of seismic performance of interior RC beam-column joints strengthened with FRP composites. Eng. Struct. 2019, 196, 109308. [CrossRef]

42. Pohoryles, D.A.; Rossetto, T. A critical evaluation of current design guidelines for the seismic retrofit of beam-column joints with FRP. In Proceedings of the 2nd Second European Conference on Earthquake Engineering and Seismology, Istanbul, Turkey, 25-29 August 2014. [CrossRef]

43. Pauletta, M.; Di Marco, C.; Frappa, G.; Somma, G.; Pitacco, I.; Miani, M.; Das, S.; Russo, G. Semi-empirical model for shear strength of RC interior beam-column joints subjected to cyclic loads. Eng. Struct. 2020, 224. [CrossRef]

44. European Commitee for Standardization. Eurocode 8: Design of structures for earthquake resistance-Part 1: General rules, Seismic Actions and Rules For Buildings. Eur. Comm. Stand. 2004, 1, 1-229.

45. ACI. ACI 352R-02 Recommendations for Design of Beam-Column Connections in Monolithic Reinforced Concrete Structures (ACI-ASCE 352-02); Technical Report; ACI: Farmington Hills, MI, USA, 2002.

46. Paulay, T.; Priestly, M.J.N. Seismic Design of Reinforced Concrete and Masonry Buildings, 1st ed.; John Wiley \& Sons, Inc.: New York, NY, USA, 1992; p. 744. 